\title{
Variabilidade genética para caracteres morfológicos e fisiológicos em espinheira- santa (Maytenus ilicifolia (Schrad.) Planch. e M. aquifolium Mart.)
}

\author{
MARIOT, M.P. ${ }^{4}$; BARBIERI, R.L. ${ }^{*}$; CORREAA, F. ; BENTO, L.H.G. ${ }^{3}$ \\ 'Universidade Federal de Pelotas, Av. Ildefonso Simões Lopes, 2791, Pelotas-RS, CEP: 96.060-290 \\ mariot@ufpel.edu.br ${ }^{2}$ Embrapa Clima Temperado, BR 392, km 78, Caixa Postal 403, Pelotas/RS, CEP96.001- \\ 970 *barbieri@cpact.embrapa.br ${ }^{3}$ Universidade Católica de Pelotas, Pelotas/RS - Bolsista de Iniciação Científica \\ da FAPERGS; ${ }^{4}$ Bióloga, mestranda do Curso de pós-graduação em Biologia Vegetal, UFSC, Florianópolis/SC.
}

\begin{abstract}
RESUMO: O objetivo deste trabalho foi avaliar a variabilidade genética, estimar parâmetros genéticos e a correlação entre caracteres morfo-fisiológicos em progênies de meios-irmãos de 93 acessos de espinheira-santa do banco ativo de germoplasma da Embrapa Clima Temperado. Foram analisados os caracteres dias da semeadura à emergência; estatura de planta; diâmetro à base do caule; número de folhas por planta; taxa de crescimento em estatura e em diâmetro à base do caule, comprimento e largura de folha e número de espinhos por folha. O delineamento experimental foi em blocos casualizados, com quatro repetições e cinco plantas por parcela. Os dados foram submetidos à análise da variância e comparação entre médias e foram estimados os parâmetros genéticos herdabilidade, coeficiente de variação genético (CVG) e relação entre coeficiente de variação genético e coeficiente de variação do erro experimental (CVE) $(\hat{b})$,bem como as correlações fenotípicas entre os caracteres. Foi identificada variabilidade genética para todos os caracteres. As variâncias de ambiente foram baixas e as variâncias genotípicas foram altas, o que resultou em altos valores de herdabilidade. Os CVG foram altos e os CVE foram baixos, o que levou a elevados valores para o quociente $\hat{b}$. Estes parâmetros são importantes na seleção para estes caracteres em programas de melhoramento. Foram identificadas correlações significativas entre os caracteres morfo-fisiológicos.
\end{abstract}

Palavras-chave: plantas medicinais, recursos genéticos, parâmetros genéticos, correlação

ABSTRACT: Genetic variability for morphologic and physiologic traits in "espinheirasanta" (Maytenus ilicifolia (Schrad.) Planch. and M. aquifolium Mart.). The aim of this work was to evaluate the genetic variability, as well as to estimate genetic parameters and correlations among morphophysiologic traits in half-brother progenies from 93 sources of "espinheirasanta" from the active germplasm bank of "Embrapa Clima Temperado". The analyzed traits were days from sowing to emergence; plant height; stem basal diameter; leaf number per plant; height and stem basal diameter growth rate; leaf length and width; and thorn number per leaf. The experimental design was in randomized blocks, with four replicates and five plants per plot. Data were subjected to analysis of variance and comparison of means. The genetic parameters heritability, coefficient of genetic variation (CGV), a(nd) atio between the coefficient of genetic variation and the coefficient of experimental error variation (CEV) were assessed. Phenotypic correlations among traits were also estimated. Genetic variability was identified for all traits. Environment variances were low and genotypic variances were high, resulting in high heritability values. CGV were high and CEV were low, leading to high $\hat{b}$ quotient values. These parameters are important for the selection of these traits in breeding programs. Significant correlations among morphophysiologic traits were identified.

Key words: medicinal plants, genetic resources, genetic parameters, correlation

Recebido para publicação em 22/04/2008

Aceito para publicação em 19/06/2009 


\section{INTRODUÇÃO}

Maytenus ilicifolia (Schrad.) Planch. e M. aquifolium Mart. são espécies autóctones e apresentam alto valor medicinal contra gastrite e úlcera gástrica, com ação comprovada por Carlini (1988). Ambas as espécies são alógamas e compartilham alelos (Perecin \& Kageyama, 2002). Pelo alto valor medicinal, tem sido amplamente utilizada pela medicina popular e a crescente demanda tem levado a extrativismo predatório, resultando em erosão genética. Neste sentido, para preservar a variabilidade genética, utilizando a conservação ex situ, a Embrapa Clima Temperado implantou em 2002 um banco ativo de germoplasma (BAG) de espinheira-santa.

Existem poucos estudos com relação à variabilidade genética e à estimativa de parâmetros genéticos para caracteres morfológicos e fisiológicos agronomicamente importantes em espinheira-santa. Estes estudos, possibilitados por meio de teste de progênies, servem de suporte para trabalhos de melhoramento e conservação de recursos genéticos. A importância de variáveis quantitativas, como a produção de biomassa, para a seleção de genótipos superiores em M. ilicifolia foi destacada por Radomski \& Scheffer (2004). Em teste de progênie, os autores identificaram uma ampla variação para o crescimento em estatura. Como a taxa de crescimento desta espécie é bastante lenta (Rachwal et al., 1997; Nicoloso et al., 2000), a seleção de plantas com maiores taxas de crescimento e que possuam maior produção de biomassa pode, portanto, ser estratégia adequada em programas de melhoramento de espinheira-santa.

A alta herdabilidade para o caráter estatura de planta em espinheira-santa, identificada por Scheffer (2001), contribui para eficiência no melhoramento. Os caracteres de morfologia foliar também são importantes para a observação de aspectos relacionados à produção de biomassa. De acordo com Bernardi \& Wasicki (1959), folhas de $M$. ilicifolia desenvolvidas a pleno sol eram menores, com espinhos nas margens em número reduzido e apresentavam maior concentração de taninos. Radomski et al. (2004) observaram que as folhas de espinheira-santa desenvolvidas em ambiente com alta luminosidade, eram menores, com peso específico maior, mais amareladas, mais espessas e com espinhos mais pronunciados, o que caracterizam adaptação de plantas de sombra à luz solar total.

Ao estudar a variabilidade em duas populações de $M$. ilicifolia em Santa Catarina, Steenbock et al. (2003) observaram que apesar da biomassa foliar dos indivíduos ter sido semelhante nas duas populações, a disposição desta biomassa foi diferente. As plantas cuja população se desenvolvia a pleno sol apresentaram área foliar e massa de folhas menores do que as da outra população, que era parcialmente sombreada.
O objetivo deste trabalho foi identificar a variabilidade genética e estimar parâmetros genéticos para caracteres morfológicos e fisiológicos em progênies de meios-irmãos de espinheira-santa, bem como a correlação entre estes caracteres.

\section{MATERIAL E MÉTODO}

Foram avaliadas as progênies de 93 acessos de espinheira-santa - oriundos de populações do Rio Grande do Sul - do banco ativo de germoplasma da Embrapa Clima Temperado. Por se tratarem de espécies alógamas, as progênies são de irmãos maternos. As populações estudadas foram: Metade Sul do Estado: Encruzilhada do Sul 1 (acessos 1 ao 7); Encruzilhada do Sul 2 (acessos 8 ao 16); Piratini 1 (acesso 18); Piratini 2 (acessos 19, 20, 24 ao 26, 28, 30 ao 39 e 41); Piratini 3 (acessos 44 ao 54); Arroio Grande 1 (acessos 55, 56, 86 e 87); Arroio Grande 2 (acesso 57); Arroio Grande 3 (acesso 59); Arroio Grande 4 (acessos 60 e 92); Arroio Grande 5 (acesso 61); Candiota 1 (acessos 62 ao 64, 66 ao 69 e 71 ao 75); Candiota 2 (acessos 76 ao 83); Hulha Negra (acesso 84); Pelotas (acesso 85); Arroio Grande 6 (acessos 88 e 89) e Arroio Grande 7 (acessos 93 e 94); Região Nordeste do Estado: Farroupilha 1 (acesso 90); Farroupilha 2 (acesso 91); Caxias do Sul (acesso 101); Vacaria 1 (acesso 102); Esmeralda (acessos 103, 104, 106, 107, 110 e 111); Vacaria 2 (acesso 105) e São Marcos (acesso 113); Região Metropolitana de Porto Alegre: Cachoeirinha (acesso 95).

Os nomes das populações correspondem aos municípios onde foram feitas as coletas e os números dos acessos correspondem às matrizes que originaram as progênies de meios-irmãos. Cada família de progênies de meios-irmãos corresponde a um número de acesso no Banco Ativo de Germoplasma (ex.: acesso 1 corresponde a uma família de meiosirmãos originários de uma planta matriz a qual se atribuiu o número 1) e as informações sobre os acessos estão disponíveis na Embrapa Clima Temperado. Os acessos 90, 91, 110 e 113 pertencem à espécie $M$. aquifolium e os demais a $M$. ilicifolia.

Sementes coletadas entre os meses de novembro de 2002 e janeiro de 2003 foram semeadas em fevereiro de 2003 em sacos de polietileno preto, em telado na Embrapa Clima Temperado, num total de 50 sementes por acesso, para produção final de 20 progênies de meios-irmãos por acesso. $O$ substrato utilizado foi areia, esterco bovino curtido e terra, na proporção de 1:1:1. Foi colocado sombrite $50 \%$ - o qual permaneceu entre fevereiro e abril de 2003 - para permitir melhor desenvolvimento das mudas na fase inicial. Em abril de 2003 as mudas foram transferidas para casa-de-vegetação e em novembro de 2003, elas foram transplantadas para canteiros de alvenaria em área de telado. Aadubação 
utilizada foi: esterco bovino $\left(7,7 \mathrm{~kg} \mathrm{~m}^{-2}\right)$; adubo NPK 10-20-10 (9,6 $\left.\mathrm{g} \mathrm{m}^{-2}\right)$ e nitrocálcio $\left(41,7 \mathrm{~g} \mathrm{~m}^{-2}\right)$.

Os caracteres avaliados foram número de dias da semeadura à emergência; estatura de planta $(\mathrm{cm})$ e diâmetro à base do caule $(\mathrm{mm})$ - avaliados aos 360 dias após a semeadura; número de folhas/ planta - avaliado aos 180 dias após a semeadura; taxas de crescimento em estatura $\left(\mathrm{cm} \mathrm{dia}^{-1}\right)$ e em diâmetro à base do caule $\left(\mathrm{mm} \mathrm{dia}^{-1}\right)$ - avaliadas a partir das diferenças entre as estaturas e entre os diâmetros aos 360 e 90 dias, dividido por 270 dias; comprimento $(\mathrm{cm})$ e largura de folha $(\mathrm{cm})$ e número de espinhos/folha.

Os dados referentes aos caracteres de morfologia foliar foram baseados na média de três folhas, retiradas da parte inferior, mediana e superior de cada planta. Para maior homogeneidade das variâncias e para atender a pressuposição de normalidade na análise, os dados das variáveis estatura de planta, diâmetro da base do caule e crescimento em estatura foram transformados para raiz quadrada e dias da semeadura à emergência, para o logaritmo de base 10 dos dados originais $(\log 10)$.

O delineamento experimental foi em blocos casualizados, com quatro repetições e cinco plantas por parcela. Os dados foram submetidos à análise de variância, utilizando-se o programa estatístico SAS, versão 8.2 (SAS Institute, 2000) e a comparação entre médias foi realizada pelo teste de Scott e Knott (Scott \& Knott, 1974), com auxílio do programa GENES (Cruz, 2001). Os componentes da variância, bem como, os parâmetros genéticos herdabilidade com base na média de parcelas $-h_{\mu}^{2}$, coeficiente de variação genético - $C V_{G}$ e relação entre $C V_{G}$ e $C V_{E}$ (coeficiente de variação do erro experimental) $-\hat{b}$, foram estimados conforme descrito por Vencovsky \& Barriga (1992), baseado em média de parcelas, utilizando-se o modelo matemático $Y_{i j}=m+G_{i}+B$ $+e_{i j}$, em que o valor $Y_{i j}$, refere-se à observação da $i-$ ésima família, do j-ésimo bloco; $m$ é a média geral;
$G_{i}$ é o efeito da i-ésima família; $B_{j}$ é o efeito do jésimo bloco; ;é o efeito aleatório ambiental existente entre parcelas. Foram estimadas ainda as correlações fenotípicas entre os caracteres por meio do coeficiente de Pearson ( $r$ ), tendo a significância sido testada pela estatística t, conforme descrito por Carvalho et al. (2004). Esta análise foi realizada com auxílio do programa GENES (Cruz, 2001).

Para este trabalho, os acessos do banco ativo de germoplasma de espinheira-santa foram considerados como pertencentes a uma metapopulação, em que interessava saber o efeito de cada acesso, representado por uma família de irmãos maternos. Os acessos foram, portanto, considerados como efeito fixo.

\section{RESULTADO E DISCUSSÃO}

Os dados permitiram identificar a existência de variabilidade genética para todos os caracteres avaliados em progênies de meios-irmãos dos acessos de espinheira-santa (Tabela 1). Os coeficientes de variação foram baixos para a maioria dos caracteres, sendo considerados médios para número de folhas por planta e crescimento em diâmetro à base do caule, o que mostra aceitável precisão experimental.

O caráter dias da semeadura à emergência apresentou uma ampla variação. Os 18 acessos (2-6, $8-12,15,16,18,28,30,32,33,50$ e 84) que apresentaram emergência mais rápida são todos da espécie $M$. ilicifolia e oriundos de populações localizadas em municípios da Metade Sul do Rio Grande do Sul. Entre os seis acessos, também pertencentes à espécie $M$. ilicifolia, que apresentaram maior número de dias para emergência, três são oriundos da Metade Sul (20,51 e 85) e três da Região Nordeste do Estado (102, 106 e 107). Grande variação no tempo de emergência também foi identificada em progênies de M. ilicifolia por Scheffer (2001). O autor sugere que este fato pode estar associado à existência

TABELA1. Resumo da análise da variância para nove caracteres em espinheira-santa.

\begin{tabular}{|c|c|c|c|c|c|c|c|c|c|}
\hline & $D S E^{1}$ & $E P^{2}$ & $D B C^{3}$ & $N F^{4}$ & $T C E^{5}$ & $T C D^{6}$ & $C F^{7}$ & $L F^{8}$ & $N E^{9}$ \\
\hline $\mathbf{Q M G}^{10}$ & $0,034^{\star *}$ & $1,82^{* *}$ & $0,202^{* *}$ & $7,07^{\star *}$ & $0,007^{\star *}$ & $5,1 \times 10^{-5 * *}$ & $4,40^{\star *}$ & $0,29^{\star *}$ & $29,59^{\star *}$ \\
\hline $\mathrm{CV}^{11}(\%)$ & 4,07 & 7,81 & 7,38 & 11,93 & 8,88 & 17,19 & 7,21 & 7,30 & 7,26 \\
\hline Média & 39,97 & 25,06 & 5,07 & 7,67 & $0,82 \times 10^{-1}$ & $1,63 \times 10^{-2}$ & 5,85 & 2,46 & 14,82 \\
\hline $\mathrm{GL}_{\text {Resíduo }}$ & 250 & 249 & 253 & 252 & 251 & 256 & 253 & 251 & 252 \\
\hline Amplitude & $\begin{array}{c}23,14- \\
66,53 \\
\end{array}$ & $\begin{array}{l}10,45- \\
51,63\end{array}$ & $\begin{array}{c}0,38- \\
1,79\end{array}$ & $\begin{array}{c}2,43- \\
8,06 \\
\end{array}$ & $\begin{array}{l}0,73- \\
2,64 \\
\end{array}$ & $\begin{array}{l}3,66- \\
12,01 \\
\end{array}$ & $\begin{array}{l}4,86- \\
11,75 \\
\end{array}$ & $\begin{array}{l}1,96- \\
3,82\end{array}$ & $\begin{array}{l}10,80- \\
28,04 \\
\end{array}$ \\
\hline
\end{tabular}

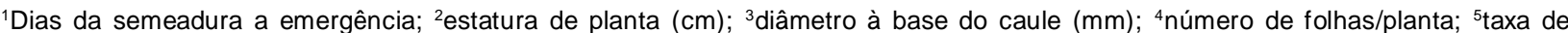
crescimento em estatura $\left(\mathrm{cm} . \mathrm{dia}^{-1}\right) ;{ }^{6}$ taxa de crescimento em diâmetro a base do caule (mm.dia-1); ${ }^{7}$ comprimento de folha $(\mathrm{cm}) ;{ }^{;} \mathrm{largura}$ de folha $(\mathrm{cm}) ;{ }^{9}$ número de espinhos/folha. ${ }^{10}$ Quadrado médio do genótipo; ${ }^{11}$ coeficiente de variação. ${ }^{*}$ Significativo a $1 \%$ de probabilidade de erro pelo teste $\mathrm{F}$. 
de maior ou menor grau de dormência nas sementes.

A estatura de planta variou de 10,45 a 51,63 $\mathrm{cm}$ e a taxa de crescimento em estatura de 0,38 a $1,79 \times 10^{-1} \mathrm{~cm} \mathrm{dia-1}$ (Tabela 1). Os acessos que apresentaram maior magnitude para estes caracteres $(101,104,105,107,110$ e 111) são todos oriundos da Região Nordeste do Estado, sendo que o acesso 110 é da espécie $M$. aquifoliume os demais são da espécie M. ilicifolia. Com exceção do acesso 102, de Vacaria, todos os que apresentaram menores valores para estes caracteres $(19,20,85)$ são oriundos da Metade Sul do Estado e são M. ilicifolia. Uma grande variação na estatura de planta também foi identificada por Scheffer (2001) em M. ilicifolia aos 11, 23 e 38 meses de idade em dois municípios do Paraná. Radomski \& Scheffer (2004) observaram um incremento médio em estatura de $31,8 \mathrm{~cm}$, entre os 23 e os 75 meses de idade em M. ilicifolia.

Magalhães et al. (1992) identificaram estatura média de $25 \mathrm{~cm}$ entre as melhores plantas de $M$. ilicifolia, com um ano de idade, o que corresponde à média identificada neste trabalho em período semelhante. Os autores observaram que até o sétimo mês as plantas apresentaram taxa baixa de crescimento, tendo ocorrido maior incremento a partir do oitavo mês. Segundo os autores, este comportamento parece ser próprio da fisiologia da espécie e talvez o aumento no fotoperíodo tenha influenciado na indução do crescimento vegetativo. Devem ser consideradas, além das diferenças genéticas entre as plantas avaliadas a existência de diferenças de ambiente e de idade das plantas entre os dois trabalhos.

O caráter diâmetro à base do caule variou de 2,43 a $8,06 \mathrm{~mm}$ e a taxa de crescimento em diâmetro à base do caule variou de 0,73 a 2,64 x 10${ }^{2} \mathrm{~mm}$.dia ${ }^{-1}$ (Tabela 1). Com exceção do acesso 32, de Piratini, todos os que apresentaram os maiores diâmetros (104, 107, 110 e 111) são de Esmeralda, sendo que o acesso 110 é $M$. aquifolium, enquanto os demais são M. ilicifolia. Os acessos que apresentaram os menores valores para o caráter diâmetro a base do caule $(7,20,59,79,80$, 85 e 102) são todos oriundos da Metade Sul do Estado, com exceção do acesso 102, de Vacaria e do 90, de Farroupilha (somente para o caráter crescimento em diâmetro à base do caule). Grande variação para este caráter $(0,6$ a 2,6 mm) também foi observada por Scheffer (2001), em plantas de M. ilicifolia aos 11 meses de idade. Para esta mesma espécie, Nicoloso et al. (2000) identificaram um diâmetro médio de 0,75 $\mathrm{mm}$ aos 135 dias após a semeadura.

A maior estatura e diâmetro do caule observados nas progênies de acessos oriundos da Região Nordeste do Estado corroboram com os resultados relatados por Mariot (2005), em plantas matrizes daquela Região que, diferentemente das outras regiões em que foram feitas coletas, eram plantas de porte arbóreo, com estatura e diâmetro à base do caule maiores.

O número de folhas por planta variou de 3,66 a 12,01 (Tabela 1). O acesso 30, de Piratini, e os acessos 104 e 111, de Esmeralda, apresentaram os maiores valores para este caráter. Para esta mesma espécie, Magalhães et al. (1992) identificaram para média das melhores plantas, aos 6 meses, 9,5 folhas/ planta, valor que foi superior à média obtida neste trabalho, para o mesmo período. Em estudo comparativo entre duas populações naturais de $M$. ilicifolia, Steenbock et al. (2003) não observaram diferença no número de folhas por planta.

Para os caracteres de morfologia foliar foi evidenciada ampla variabilidade (Tabela 1). $O$ acesso 91, de Farroupilha, pertencente à espécie M. aquifolium, foio que apresentou folhas maiores e com maior número de espinhos por folha. Os acessos de M. aquifolium se destacaram para estes caracteres. Estes resultados estão de acordo com os apresentados por CarvalhoOkano (1992). Alta variabilidade para caracteres de morfologia foliar em espinheira-santa foi identificada em matrizes de onde foram retiradas sementes para a formação do banco ativo de germoplasma da Embrapa Clima Temperado (Mariot, 2005).

Segundo Radomski \& Scheffer (2004), no Rio Grande do Sul predominam plantas de M. ilicifolia com folhas largas e curtas, coriáceas, com espinhos longos distribuídos ao longo de todo o limbo. Esta caracterização é importante para a descrição de acessos de $M$. ilicifolia, entretanto, o fato de envolver caracteres qualitativos e em populações de apenas dois municípios do Rio Grande do Sul, dificulta a comparação com os resultados deste trabalho. Vários autores observaram que plantas desenvolvidas em pleno sol apresentam folhas menores (Steenbock et al., 2003; Radomski et al., 2004). Ainda, segundo Bernardi \& Wasicki (1959), folhas de M. ilicifolia desenvolvidas a pleno sol apresentavam espinhos nas margens em número reduzido. As progênies avaliadas neste trabalho somente ficaram em condições de sombreamento na fase inicial de desenvolvimento, entre março e abril de 2003, passando a maior parte do tempo em pleno sol. Acessos como o 91, que é oriundo de matriz que apresentava folhas grandes (Mariot, 2005), mostraram nas progênies folhas também grandes, 0 que evidencia forte fator genético controlando estes caracteres e não somente o ambiente.

A conservação ex situ de espinheira-santa é importante, principalmente por ser espécie ameaçada de extinção e a ampla variabilidade identificada neste trabalho mostra a boa representatividade dos acessos como recursos genéticos em banco de germoplasma.

Os valores de herdabilidade foram altos para todos os caracteres (Tabela 2). Este caráter é importante para a seleção de genótipos superiores em programas de melhoramento. 
TABELA2. Estimativa dos componentes da variância $\hat{\sigma}_{E}^{2}$ (variância de ambiente), $\hat{\phi}_{G}^{2}$ (variância genética) e $\hat{\sigma}_{P}^{2}$ (variância fenotípica) e dos parâmetros genéticos herdabilidade com base na média $\left(h_{\mu}^{2}\right)$, coeficiente de variação genético $\left(C V_{G}\right)$ e relação entre $C V_{G}$ e coeficiente de variação do erro experimental $\left(C V_{E}\right)(\hat{b})$ para nove caracteres em progênies de meios-irmãos de espinheira-santa.

\begin{tabular}{llllllllll}
\hline & \multicolumn{10}{c}{ Caracteres } \\
\cline { 2 - 10 } & DSE $^{1}$ & EP $^{2}$ & DBC $^{3}$ & NF$^{4}$ & TCE $^{5}$ & TCD $^{6}$ & CF $^{7}$ & LF $^{8}$ & NE $^{9}$ \\
\hline$\hat{\sigma}_{E}^{2}$ & 0,0042 & 0,1495 & 0,0273 & 0,8379 & 0,0006 & 0,000008 & 0,1783 & 0,0321 & 1,1597 \\
$\hat{\phi}_{(i}^{2}$ & 0,0075 & 0,4185 & 0,0436 & 1,5584 & 0,0015 & 0,000011 & 1,0546 & 0,0649 & 7,1070 \\
$\hat{\sigma}_{P}^{2}$ & 0,0085 & 0,4559 & 0,0504 & 1,7678 & 0,0017 & 0,000013 & 1,0992 & 0,0729 & 7,3969 \\
$h_{\mu}^{2}$ & 0,88 & 0,92 & 0,86 & 0,88 & 0,91 & 0,85 & 0,96 & 0,89 & 0,96 \\
$\mathbf{C V}_{\mathbf{G}}(\%)$ & 5,46 & 13,07 & 9,33 & 16,27 & 13,78 & 20,16 & 17,54 & 10,37 & 17,98 \\
$\hat{b}$ & 1,34 & 1,67 & 1,26 & 1,36 & 1,55 & 1,17 & 2,43 & 1,42 & 2,48 \\
\hline
\end{tabular}

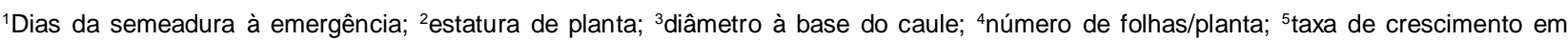
estatura; ${ }^{6}$ taxa de crescimento em diâmetro à base do caule; ${ }^{7}$ comprimento de folha; ${ }^{8}$ largura de folha; ${ }^{9}$ número de espinhos/folha.

O coeficiente de variação genético foi baixo para o caráter dias da semeadura à emergência e alto para os demais caracteres (Tabela 2), comparável aos resultados de Sebbenn et al. (1998, 1999), com outras espécies florestais nativas, e os coeficientes de variação devido ao erro experimental foram baixos (Tabela 1) para todos os caracteres, o que proporcionou quociente $\hat{b}$ alto para as variáveis analisadas (Tabela 2). Segundo Vencovsky \& Barriga (1992), na experimentação com progênies de meiosirmãos, quando este quociente atinge valor igual ou maior que 1,0 indica situação favorável para seleção. Os valores de $\hat{b}$ apresentados neste trabalho são, portanto, indicadores da potencialidade para seleção de genótipos superiores para todos os caracteres analisados.

Com valores do coeficiente de variação genético acima de $7 \%$ para estatura em cabreúva (Myroxylon peruiferum), Sebbenn et al. (1998) consideraram este parâmetro como de alta magnitude. Segundo os autores, este resultado é devido ao fato de que a população foi composta por progênies de quatro populações naturais diferentes, ocasionando incremento na variabilidade genética, o que também corresponde ao evidenciado neste trabalho, em que as progênies são oriundas de matrizes de vários locais diferentes. Em trabalho desenvolvido com a espécie arbórea Pterogyne nitens, Sebbenn et al. (1999) também observaram altos valores para o coeficiente de variação genético para estatura e diâmetro à altura do peito (10 a 20\%).

A conservação in situ pode ser inviabilizada em populações que se encontram fragmentadas e constituídas por pequeno número de exemplares. A conservação ex situ multipopulacional seria estratégia interessante nesta situação, em que seria incluído o maior número possível de famílias e de populações oriundas de várias localidades, para tornar mais eficiente o programa de conservação. Esta foi a estratégia de conservação da variabilidade genética de espinheira-santa adotada pelo BAG, uma vez que a maioria das populações amostradas era pequena. As estimativas dos parâmetros genéticos nas progênies mostram que uma parcela importante da variabilidade genética foi detectada para caracteres de interesse agronômico, o que pode ser útil em programas de melhoramento. Este resultado evidencia a eficiência na estratégia de conservação do germoplasma de espinheira-santa.

Por ser espécie de crescimento lento, a seleção de genótipos com crescimento mais rápido é parâmetro importante a ser considerado em programas de melhoramento de espinheira-santa. Considerando, ainda, que o aumento da biomassa é característica importante no melhoramento de plantas medicinais (Oliveira, et al., 2003), o número de folhas por planta e o tamanho das folhas também devem ser considerados na seleção. Os parâmetros genéticos estimados neste trabalho indicam a possibilidade de exploração da variabilidade genética presente nos acessos avaliados para tais características.

Foram evidenciadas correlações altamente significativas para vários caracteres avaliados (Tabela 3). O caráter dias da semeadura à emergência apresentou correlação significativa e negativa com os caracteres diâmetro à base do caule e número de folhas por planta, ou seja, quanto maior a velocidade de emergência, maiores os valores para estes caracteres, que estão relacionados ao crescimento. 
TABELA3. Estimativa dos coeficientes de correlações de Pearson entre os caracteres morfo-fisiológicos avaliados em progênies de meios-irmãos de espinheira-santa.

\begin{tabular}{|c|c|c|c|c|c|c|c|c|}
\hline & $D S E^{1}$ & $E P$ & $D B C$ & $N F$ & $T C E$ & $T C D$ & $\overline{C F}$ & $L F$ \\
\hline $\mathrm{EP}^{2}$ & $-0,12$ & & & & & & & \\
\hline $\mathrm{DBC}^{3}$ & $-0,34$ * & 0,58 * & & & & & & \\
\hline $\mathrm{NF}^{4}$ & $-0,43^{*}$ & 0,49 * & 0,53 * & & & & & \\
\hline $\mathrm{TCE}^{5}$ & $-0,08$ & 0,99 * & 0,58 * & 0,47 * & & & & \\
\hline TCD & $-0,26$ & 0,57 * & 0,97 * & 0,49 * & 0,59 * & & & \\
\hline $\mathrm{CF}^{7}$ & $-0,09$ & 0,44 * & $0,27^{*}$ & 0,18 & 0,40 * & 0,24 & & \\
\hline LF $^{8}$ & $-0,11$ & 0,22 & 0,13 & $-0,08$ & 0,17 & 0,07 & 0,67 * & \\
\hline $\mathrm{NE}^{9}$ & $-0,07$ & 0,39 * & 0,25 & 0,25 & 0,38 * & 0,24 & 0,82 * & 0,49 * \\
\hline
\end{tabular}

'Dias da semeadura a emergëncia; 'estatura de planta; ${ }^{3}$ diämetro a base do caule; ${ }^{4}$ número de tolhas/planta; ${ }^{3}$ taxa de crescimento em estatura; ${ }^{6}$ taxa de crescimento em diâmetro a base do caule; ${ }^{7}$ comprimento de folha; ${ }^{8}$ largura de folha; ${ }^{9}$ número de espinhos/folha. ${ }^{\star}$ Significativo a $1 \%$ de probabilidade pelo teste $\mathrm{t}$.

Os caracteres estatura de planta, diâmetro à base do caule, número de folhas por planta, taxa de crescimento em estatura e taxa de crescimento em diâmetro à base do caule apresentaram correlações altamente significativas e positivas entre si (Tabela 3). As altas correlações são aspecto positivo para seleção indireta em programas de melhoramento, conforme descrito por Carvalho et al. (2004). Para estes caracteres, relacionados ao crescimento, foram consideradas altas as correlações entre estatura e taxa de crescimento em estatura e entre diâmetro à base do caule e taxa de crescimento em diâmetro à base do caule, o que era esperado, pois a estatura e o diâmetro do caule foram utilizados para o cálculo da taxa de crescimento. As demais correlações entre os caracteres relacionados com o crescimento foram consideradas médias. Em programas de melhoramento, cujo objetivo seja a obtenção de plantas com maior taxa de crescimento, a seleção deverá ser com base na estatura e/ou no diâmetro à base do caule, caracteres que apresentaram alta herdabilidade.

Ocomprimento de folha e o número de folhas por planta, caracteres que podem ser importantes para seleção, apresentaram correlação positiva e altamente significativa com estatura de planta, diâmetro à base do caule e crescimento em estatura (Tabela 3). Estas correlações, entretanto, não são consideradas fortes. Os três caracteres de morfologia foliar apresentaram correlações positivas e altamente significativas entre si. Como o produto final de interesse em espinheira-santa éa biomassa de folhas, estratégias de seleção com base nos caracteres número de folhas e comprimento de folha seriam de maior importância. A forte correlação observada entre comprimento e largura de folha permite a seleção indireta de plantas com folhas maiores a partir de avaliações do primeiro caráter.

\section{CONCLUSÃO}

Existe ampla variabilidade genética para os caracteres morfológicos e fisiológicos nos acessos de espinheira-santa.

Há potencial para seleção em programas de melhoramento, com possibilidade de uso de seleção indireta.

Os acessos mais recomendados para o uso imediato em programas de melhoramento para os caracteres avaliados são o 104 e o 111.

\section{REFERÊNCIA}

BERNARDI, H.H.; WASICKY, M. Algumas pesquisas sobre a "Espinheira Santa" ou "Cancerosa" Maytenus ilicifolia, Martius, usada como remédio popular no Rio Grande do Sul. Santa Maria: Ed. UFRGS, 1959. 46p. CARLINI, E.A. (Coord.). Estudo da ação antiúlcera gástrica de plantas brasileiras: Maytenus ilicifolia (Espinheira-santa) e outras. Brasília: CEME/AFIP, 1988. 87p.

CARVALHO, F.I.F.; LORENCETTI, C.; BENIN, G. Estimativas e implicações da correlação no melhoramento vegetal. Pelotas: Ed. UFPel, 2004. 142p. CARVALHO-OKANO, R.M. Estudos taxonômicos do gênero Maytenus Mol. emend. Mol. (CELASTRACEAE) do Brasil extra-amazônico. 1992. 253p. Tese (Doutorado em Ciências - Biologia Vegetal) - Universidade de Campinas, Campinas.

CRUZ, C.D. Programa Genes: aplicativo computacional em genética e estatística. Viçosa: Ed.UFV, 2001. 648p. MAGALHÃES, P.M. et al. Conservação da espécie Maytenus ilicifolia Mart. ex Reiss. (espinheira-santa) através da técnica de propagação de sementes. Revista do Instituto Florestal, v.4, p.519-22, 1992.

MARIOT, M.P. Recursos genéticos de espinheira-santa (Maytenus ilicifolia e M. aquifolium) no Rio Grande do Sul. 2005. 131p. Tese (Doutorado em Agronomia - Área de Fitomelhoramento) - Universidade Federal de Pelotas, Pelotas. 
NICOLOSO, F.T. et al. Recipientes e substratos na produção de mudas de Maytenus ilicifolia e Apuleia leocarpa. Ciência Rural, v.30, n.6, p.987-92, 2000.

OLIVEIRA, J.E.Z.; AMARAL, C.L.F.; CASALI, V.W.D. Recursos genéticos e melhoramento de plantas para o nordeste brasileiro: recursos genéticos e perspectivas do melhoramento de plantas medicinais. Disponível em: <http://www.cpatsa.embrapa.br/serviços/catalogo/livrorg/ medicinaismelhoramento.doc>. Acesso em: 20 set. 2003. PERECIN, M.B.; KAGEYAMA, P.Y. Variabilidade isoenzimática em populações naturais de espinheirasanta Maytenus aquifolia Mart. e M. ilicifolia Mart. ex Reiss. e suas implicações para o manejo da conservação. Revista Brasileira de Plantas Medicinais, v.4, n.2, p.80-90, 2002.

RACHWAL, M.F.G.; CURCIO, G.R.; MEDRADO, M.J.S. Desenvolvimento e produção de massa foliar de espinheira-santa (Maytenus ilicifolia) a pleno sol, em cambissolo húmico no município de Colombo-PR. Boletim de Pesquisa Florestal, n.35, p.91-3, 1997.

RADOMSKI, M.I.; SCHEFFER, M.C. Características fenotípicas de 44 progênies de Maytenus ilicifolia Mart. cultivadas no município de Ponta Grossa, PR (Circular Técnica 86). Colombo: Embrapa Florestas, 2004. 6p. RADOMSKI, M.I. et al. Caracterização de ambientes de ocorrência natural e sua influência sobre o peso específico e o teor de polifenóis totais de folhas de espinheira-santa (Maytenus ilicifolia Mart.). Revista Brasileira de Plantas Medicinais, v.6, n.2, p.36-43, 2004. SAS INSTITUTE. SAS/STAT user's guide. Cary: Statistical Analysis System Institute, 2000. 1 CD.

SCHEFFER, M.C. Sistema de cruzamento e variação genética entre populações e progênies de espinheirasanta. 2001. 104p. Tese (Doutorado em Engenharia Florestal - Silvicultura) - Universidade Federal do Paraná, Curitiba.

SCOTT, A.J.; KNOTT, M.A. Cluster analysis methods for grouping means in the analysis of variance. Biometrics, v.30, p.507-12, 1974.

SEBBENN, A.M. et al. Parâmetros genéticos na conservação da cabreúva - Myroxylon peruiferum L.F. Allemão. Scientia Forestalis, n.53, p.31-8, 1998.

SEBBENN, A.M. et al. Variação genética entre e dentro de populações de amendoim - Pterogyne nitens. Scientia Forestalis, n.56, p.29-40, 1999.

STEENBOCK, W. et al. Avaliação de características fenotípicas para a determinação do rendimento foliar em espinheira-santa (Maytenus ilicifolia Martius). Revista Brasileira de Plantas Medicinais, v.6, n.1, p.71-6, 2003. VENCOVSKY, R.; BARRIGA, P. Genética biométrica no fitomelhoramento. Ribeirão Preto: Revista Brasileira de Genética, 1992. 486p. 